\title{
Proliferative lesions in swimbladder of Japanese medaka Oryzias latipes and guppy Poecilia reticulata
}

\author{
John W. Fournie ${ }^{1, *}$, William E. Hawkins ${ }^{2}$, William W. Walker ${ }^{1}$ \\ 'U.S. Environmental Protection Agency, National Health and Environmental Effects Research Laboratory, \\ Gulf Ecology Division, 1 Sabine Island Drive, Gulf Breeze, Florida 32561, USA \\ ${ }^{2}$ Department of Coastal Sciences, Institute of Marine Sciences, University of Southern Mississippi, PO Box 7000, \\ Ocean Springs, Mississippi 39566, USA
}

\begin{abstract}
Thirteen cases of proliferative lesions of the swimbladder were encountered in Japanese medaka Oryzias latipes and guppy Poecilia reticulata from about 10000 medaka and 5000 guppies used in carcinogenicity tests and histologically examined. Two of the 4 cases from medaka and 8 of the 9 from guppies occurred in untreated control specimens. The lesions affected the gas gland epithelium and included hyperplasia, adenoma, and adenocarcinoma. One medaka had hyperplasia of the gas gland epithelium and in 1 guppy the gland was enlarged with an increase in the number of epithelial layers. Gas gland adenomas, 3 cases in medaka and 1 in the guppy, were typically larger than the hyperplastic lesions, formed expansive masses up to $1 \mathrm{~mm}$ in greatest dimension, and exhibited a solid or glandular growth pattern and mild cellular pleomorphism. Adenocarcinoma was the most advanced Iesion and all 7 cases occurred in guppies. Adenocarcinomas sometimes filled the entire swimbladder and measured up to $2.5 \mathrm{~mm}$ in diameter. Cells of adenocarcinomas were highly pleomorphic, with atypical nuclei, and an elevated mitotic activity. Because most of these tumors occurred in fish from control groups or in tests with noncarcinogenic compounds, the lesions observed here are probably spontaneous rather than chemically induced. Their rare occurrence, however, makes swimbladder proliferative lesions in small-fish carcinogenesis models sensitive indicators of compounds that might target cells of the gas gland.
\end{abstract}

KEY WORDS: Fish $\cdot$ Swimbladder $\cdot$ Neoplasia $\cdot$ Carcinogenesis $\cdot$ Medaka $\cdot$ Guppy

\section{INTRODUCTION}

The swimbladder of fishes is generally not affected by histologically detectable lesions, especially noninfectious ones (Ferguson 1989), although some cases have been reported. Nonneoplastic lesions including hyperplasia and cellular swelling in the gas gland epithelium occurred in Japanese medaka Oryzias latipes exposed to bis(tri-n-butyltin) oxide (Wester et al. 1990), and hyperplasia of small basophilic epithelial cells on the lumenal side of the gas gland was reported in guppies Poecilia reticulata exposed to methyl mercury chloride (Wester \& Canton 1992). Neoplastic lesions of the swimbladder similarly have not been reported frequently. Neoplastic lesions diagnosed as leiomyosarcomas or fibrosarcomas associated with an infectious

•E-mail: fournie.john@epa.gov agent, probably a retrovirus, were found in $4.6 \%$ of 500 pen-reared Atlantic salmon Salmo salar on a commercial marine fish farm in Scotland (Duncan 1978, McKnight 1978). High prevalences of neoplasms of the swimbladder secretory epithelium affected medaka exposed for $28 \mathrm{~d}$ to 4 -chloroaniline and aniline (Johnson et al. 1989). In the rainbow trout Oncorhynchus mykiss, papillary adenomas of the swimbladder epithelium occurred after exposure to the carcinogens diethylnitrosamine (DEN) (Bailey et al. 1984), benzo(a)pyrene (BaP) (Hendricks et al. 1985), N-methyl-N'-nitro-Nnitrosoguanidine (MNNG) (Hendricks et al. 1980, Kimura et al. 1981, Bailey et al. 1984), N-methyl-Nnitrosourea (MNU) (Kimura et al. 1981), and dimethylnitrosomorpholine (DMNM) (Hendricks et al. 1995).

This paper reports the occurrence of swimbladder neoplasms in specimens of medaka and guppy, 2 small fish species that are used in carcinogenesis bioassays 
(Johnson et al. 1989, Hawkins et al. 1995). Here we report and describe cases of proliferative lesions of the gas gland, including hyperplasia, adenoma, and adenocarcinoma.

\section{MATERIALS AND METHODS}

Medaka and guppy evaluated for this report came from stocks maintained at the Gulf Coast Research Laboratory (Ocean Springs, Mississippi, USA) and used in toxicological studies, primarily carcinogenesis tests, since about 1984. Carcinogenesis tests were carried out generally as follows: fish approximately 6 to $10 \mathrm{~d}$ old were exposed to test chemicals for periods that ranged from $1 \mathrm{~h}$ to $180 \mathrm{~d}$ under either static or flowthrough conditions. Flow-through studies were conducted in enclosed systems similar to that described by Walker et al. (1985) and static exposures in containers within glove boxes. A typical test included equal num bers of specimens assigned to an untreated control group, a solvent control group, and 3 or more exposure groups. Following exposure, fish were transferred to 38 I grow-out aquaria maintained at $27^{\circ} \mathrm{C}$ under a $12 \mathrm{~h}: 12 \mathrm{~h}$ photoperiod. Fish were fed dry flake food 3 times and brine shrimp nauplii once daily. The growout aquaria were monitored monthly for routine waterquality parameters. Samples for histopathology were usually routinely taken at 24,36 , and $52 \mathrm{wk}$ after the beginning of exposures or when fish became moribund

Prior to fixation, most fish were anesthetized in ice water or MS-222 (tricaine methanesulfonate), the abdominal cavity was opened and the whole fish placed into Lillie's fixative (Humason 1979). To insure decalcification, specimens remained in fixative for $24 \mathrm{~h}$ to 1 wk, depending on their size. Some specimens were fixed in Bouin's fixative for $24 \mathrm{~h}$ and decalcified in a commercial decalcifying solution for 8 to $24 \mathrm{~h}$. Specimens were rinsed in water, dehydrated in ethanol, cleared in xylene or a commercial xylene substitute and embedded in paraffin. To survey most major organs, sections were taken from a mid-lateral and a median plane, mounted on glass slides, and stained with Harris' hematoxylin and eosin. In some cases, additional sections were cut and stained to verify the presence of a lesion or to confirm a diagnosis

\section{RESULTS}

\section{Normal anatomy and histology}

In the medaka and guppy, the swimbladder is located retroperitoneally in the dorsal abdominal cavity and is surrounded by a thin, fibrous tunica externa (Fig. 1). Both medaka and guppy appear to be physo-

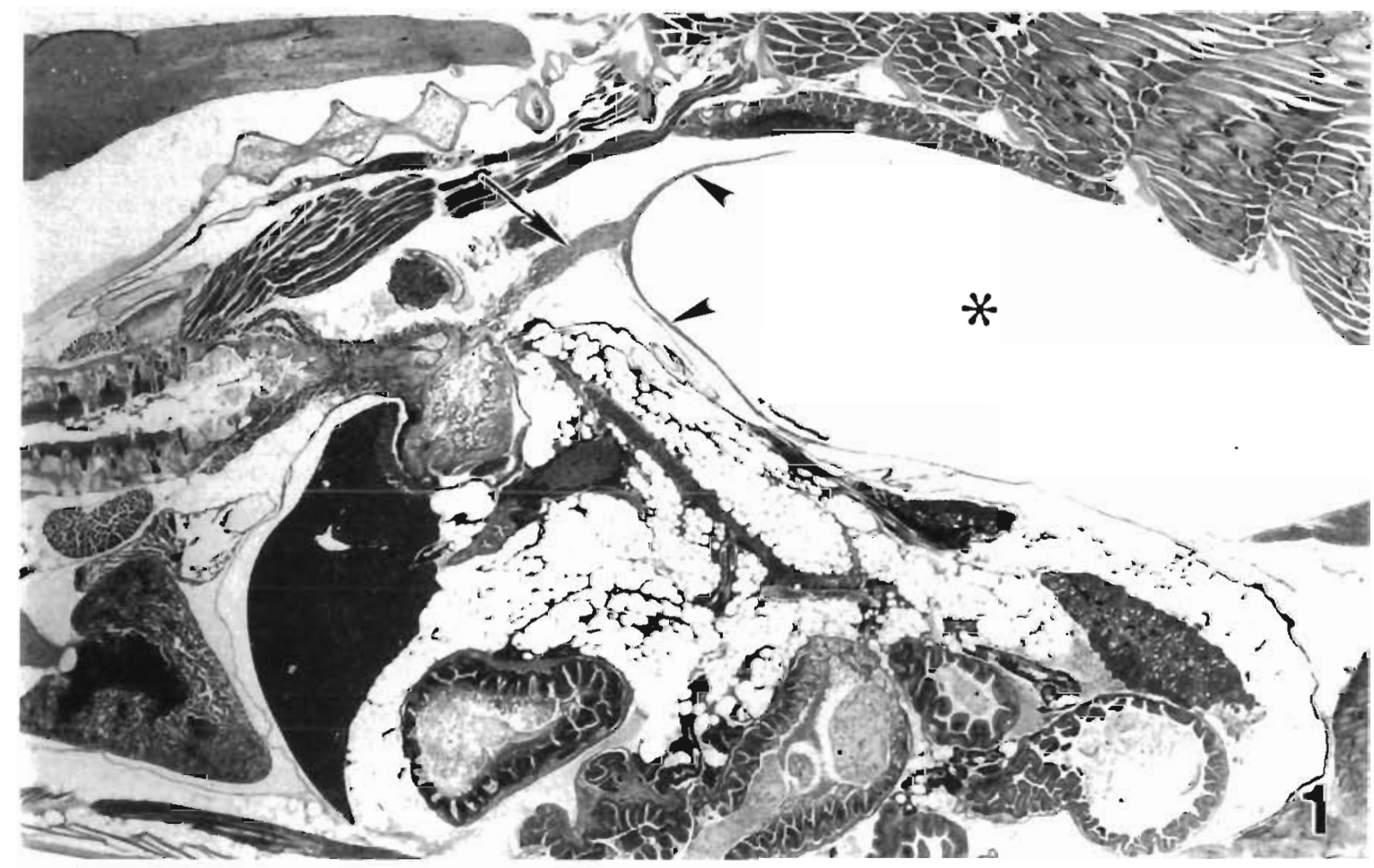

Fig. 1 Oryzias latipes. Low power view of a control Japanese medaka showing normal swimbladder structure. Note thin gas gland epithelium (arrowheads), rete mirabile (arrow), and lumen of swimbladder (asterisk). H\&E. $\times 22$ 
clists, i.e. their swimbladders do not have patent connections with the alimentary canal. The gas gland is situated at the cranial pole of the swimbladder and is composed of layers of large uniform epithelial cells with prominent eosinophilic cytoplasm. Vascularization of the gas gland is supplied by a rete mirabile, specialized for transfer of gases by a countercurrent multiplier system.

\section{Lesion prevalence}

The cases of swimbladder lesions in medaka and guppy are summarized in Table 1 . Thirteen cases were diagnosed from about $10000 \mathrm{me}$ daka and 5000 guppies older than 24 wk used in a variety of carcinogenesis tests, revealing an overall prevalence for both species of $0.09 \%$. About threefourths of the specimens were untreated control fish. The lesions arose from the gas gland epithelium and were diagnosed as hyperplasia, adenoma, or adenocarcinoma. Of the 4 medaka with lesions, 2 were males and 2 were females. One medaka with hyperplasia was from a trichloroethylene exposure, 1 with an adenoma was from a methylazoxymethanol acetate exposure, and 2 with adenomas were from control groups. Of the 9 guppies with lesions, 5 were males and 4 were females. Among
Table 1 Features of swimbladder lesions in small fish from carcinogenesis tests. $\mathrm{TCE}=$ trichloroethylene $;$ MAM-AC = methylazoxymethanol acetate; $\mathrm{CDBM}=$ chlorodibromomethane

\begin{tabular}{|ccccll|}
\hline Case & Species & Sex & Age $(w k)$ & Test group & Lesion type \\
\hline 1 & Medaka & M & 38 & TCE & Hyperplasia \\
2 & Medaka & M & 24 & Control & Adenoma \\
3 & Medaka & F & 27 & MAM-Ac & Adenoma \\
4 & Medaka & F & 36 & Control & Adenoma \\
5 & Guppy & F & 51 & Control & Hyperplasia \\
6 & Guppy & F & 13 & Control & Adenoma \\
7 & Guppy & M & 52 & Control & Adenocarcinoma \\
8 & Guppy & F & 24 & Control & Adenocarcinoma \\
9 & Guppy & M & 52 & Control & Adenocarcinoma \\
10 & Guppy & M & 52 & Control & Adenocarcinoma \\
11 & Guppy & M & 36 & Control & Adenocarcinoma \\
12 & Guppy & F & 24 & CDBM & Adenocarcinoma \\
13 & Guppy & M & 36 & Control & Adenocarcinoma \\
& & & & & \\
\hline
\end{tabular}

the guppies, single cases of hyperplasia or adenoma along with 6 of the 7 cases of adenocarcinoma occurred in control specimens. One guppy with adenocarcinoma had been exposed to chlorodibromomethane.

\section{Hyperplasia}

Hyperplasia was observed in only 2 specimens. The gas gland was enlarged with an increase in the number of epithelial cell layers (Fig. 2). Cells were vacuo-

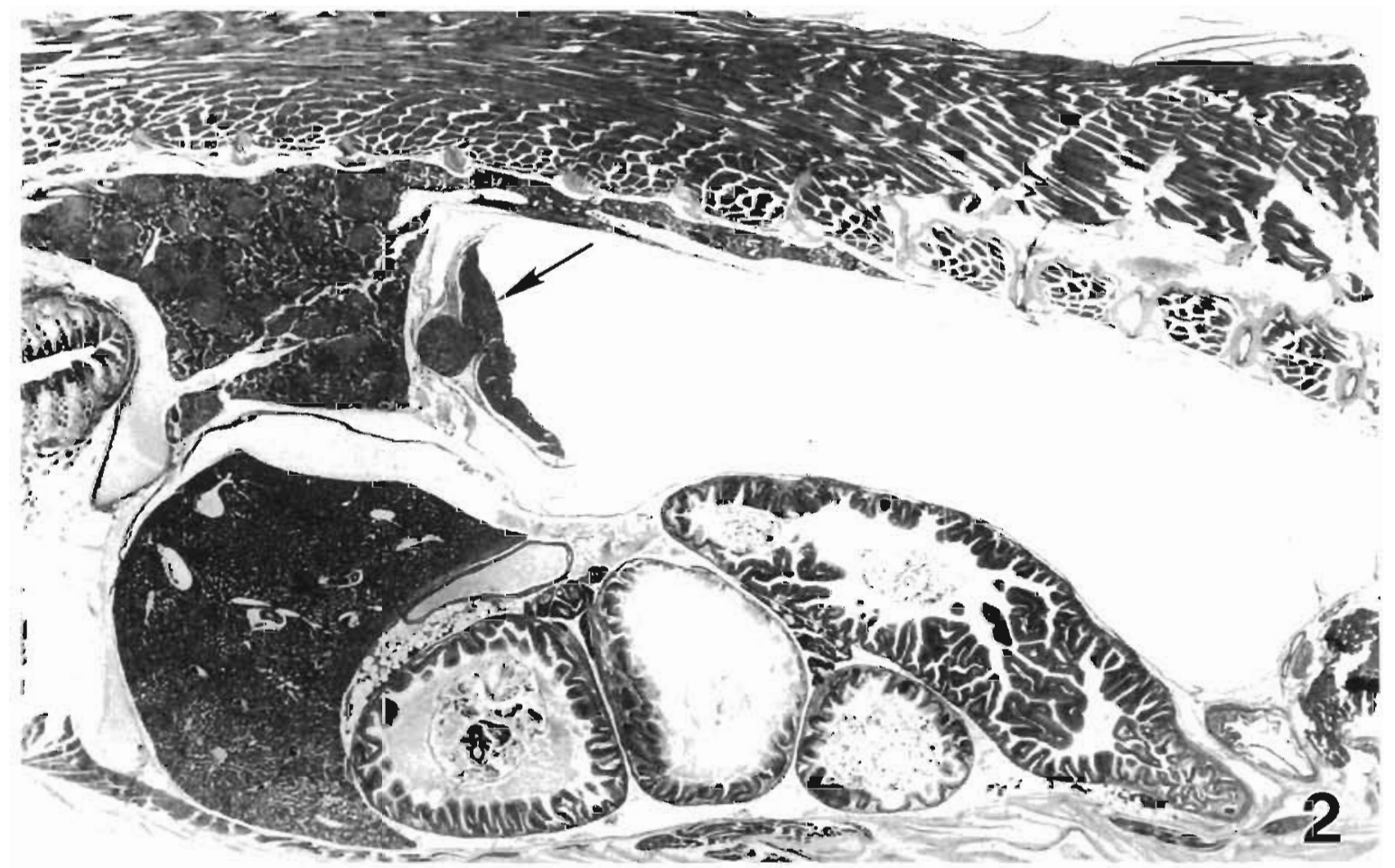

Fig. 2. Oryzias latipes. Gas gland of a medaka exposed to trichloroethylene showing distinct swelling and hyperplasia of glandular epithelium (arrow). H\&E. $\times 22$ 


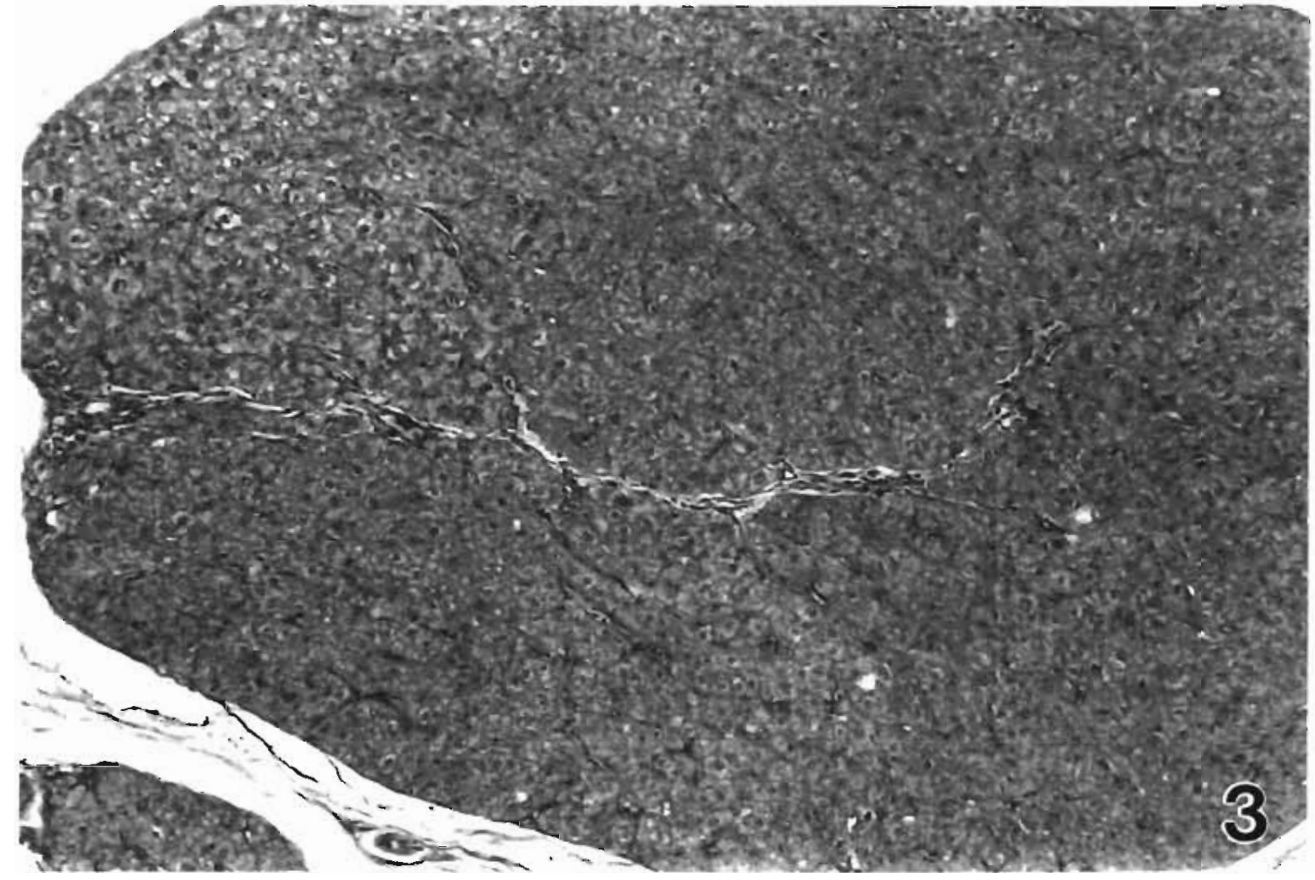

Fig. 3. Oryzias latipes. Large adenoma from a control medaka showing an expansive mass with a solid growth pattern. $H \& E . \times 200$ lated and swollen but otherwise normal, and the architecture of the epithelium was not disrupted. The fibrous tunica externa was normal.

\section{Adenoma}

Adenomas occurred in 4 specimens, 3 in medaka and 1 in a guppy, and were composed of large, eosinophilic cells with vacuolated cytoplasm that formed masses up to $1.0 \mathrm{~mm}$ in greatest dimension (Fig. 3). In contrast to hyperplastic lesions, cells of adenomas exhibited moderate cellular pleomorphism and many had irregularly shaped nuclei that contained multiple nucleoli. Some multinucleate cells were also present. One adenoma was a large solid tumor and the other 3 cases showed a prominent tubular arrangement of neoplastic cells (Fig. 4). In some cases, the tunica externa was thickened.

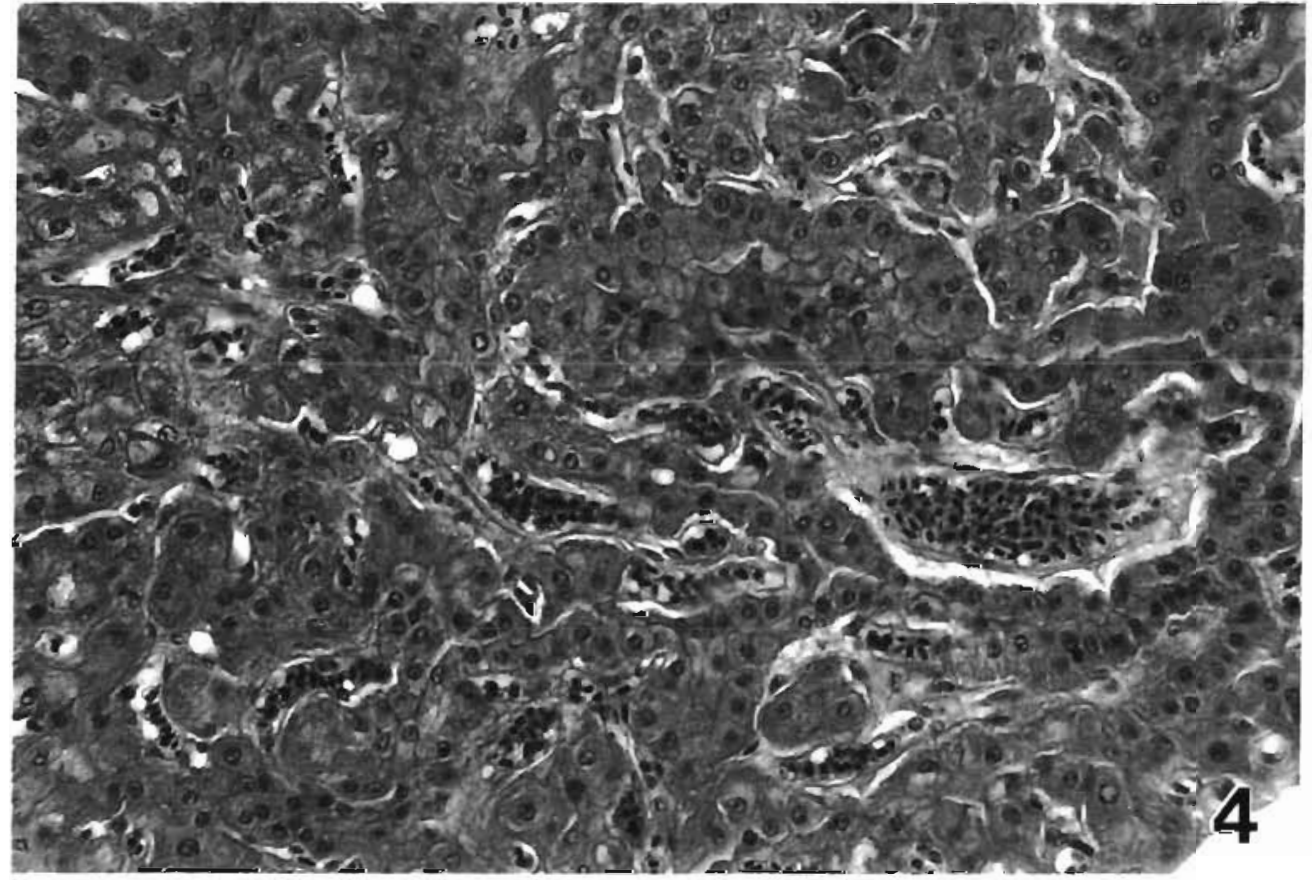

Fig. 4. Poecilia reticulata Adenoma from a control guppy showing tubular growth pattern of neoplastic cells. H\&E. $\times 400$ 


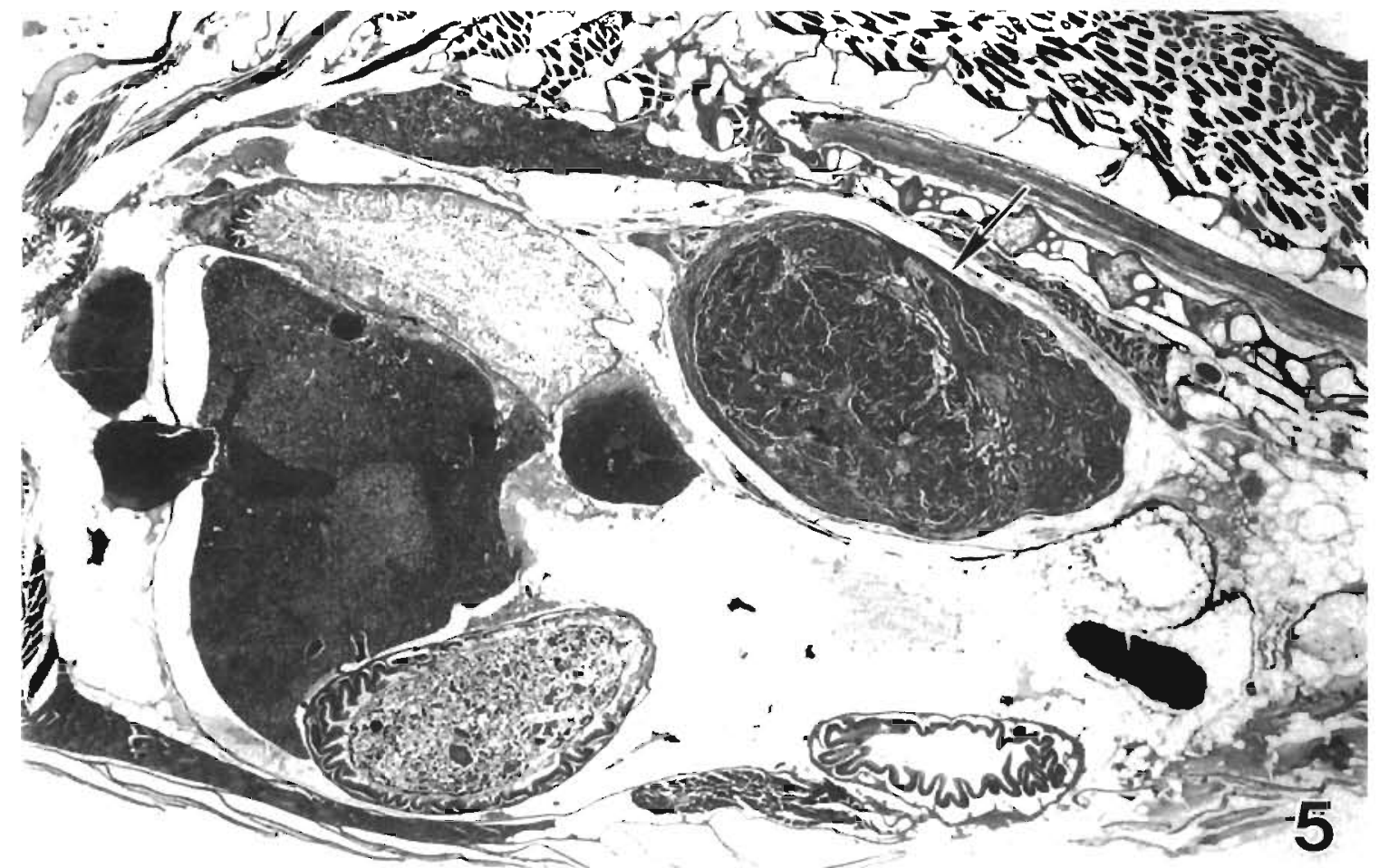

Fig. 5. Poecilia reticulata. Low-power view of a large adenocarcinoma (arrow) from a control guppy. Note the entire swimbladder is filled with tumor. H\&E. $\times 22$

\section{Adenocarcinoma}

All 7 cases of adenocarcinoma occurred in guppies and the lesions ranged in size from very small to large, tumorous masses. Some of the tumors filled the swimbladder lumen and measured up to $2.5 \mathrm{~mm}$ in greatest dimension (Fig. 5). The rete mirabile associated with adenocarcinomas usually appeared hyperplastic. Adenocarcinomas were generally characterized by large, vacuolated, eosinophilic cells that exhibited the full spectrum of anaplastic features. The smallest carcinoma was histologically the most aggressive, with constituent cells exhibiting extreme cellular pleomorphism, nuclear atypia, and elevated mitotic activity (Fig. 6). Neoplastic cells in 1 large carcinoma were arranged in a prominent glandular pattern, whereas other carcinomas exhibited a more solid pattern. The largest adenocarcinoma exhibited various cellular patterns (Fig. 5). Normal appearing gas gland epithelial cells with the typical eosinophilic cytoplasm were present at the periphery of this neoplasm (Fig. 7). An area in the posterior portion of the tumor mass was com-

Fig. 6. Poecilia reticulata. High magnification of a small adenocarcinoma from a control guppy showing extensive cellular pleomorphism and nuclear atypia. Note mitotic figures (arrowheads). H\&E. $\times 600$

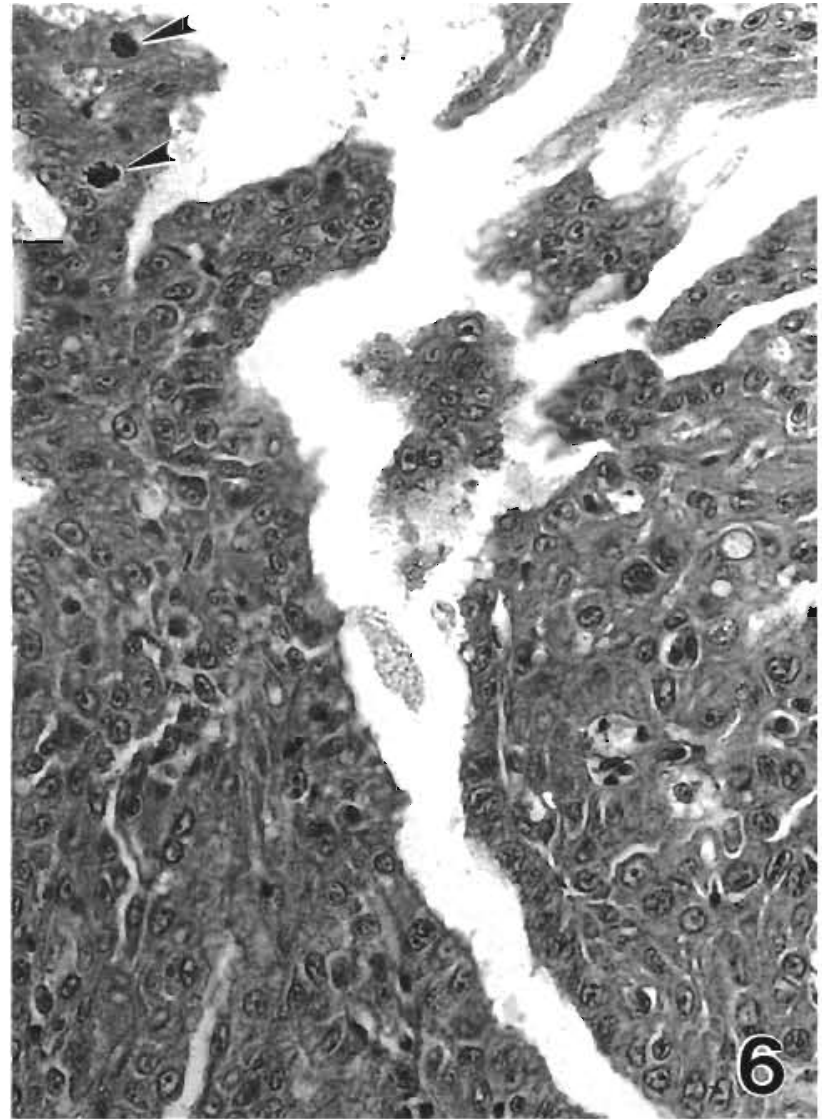




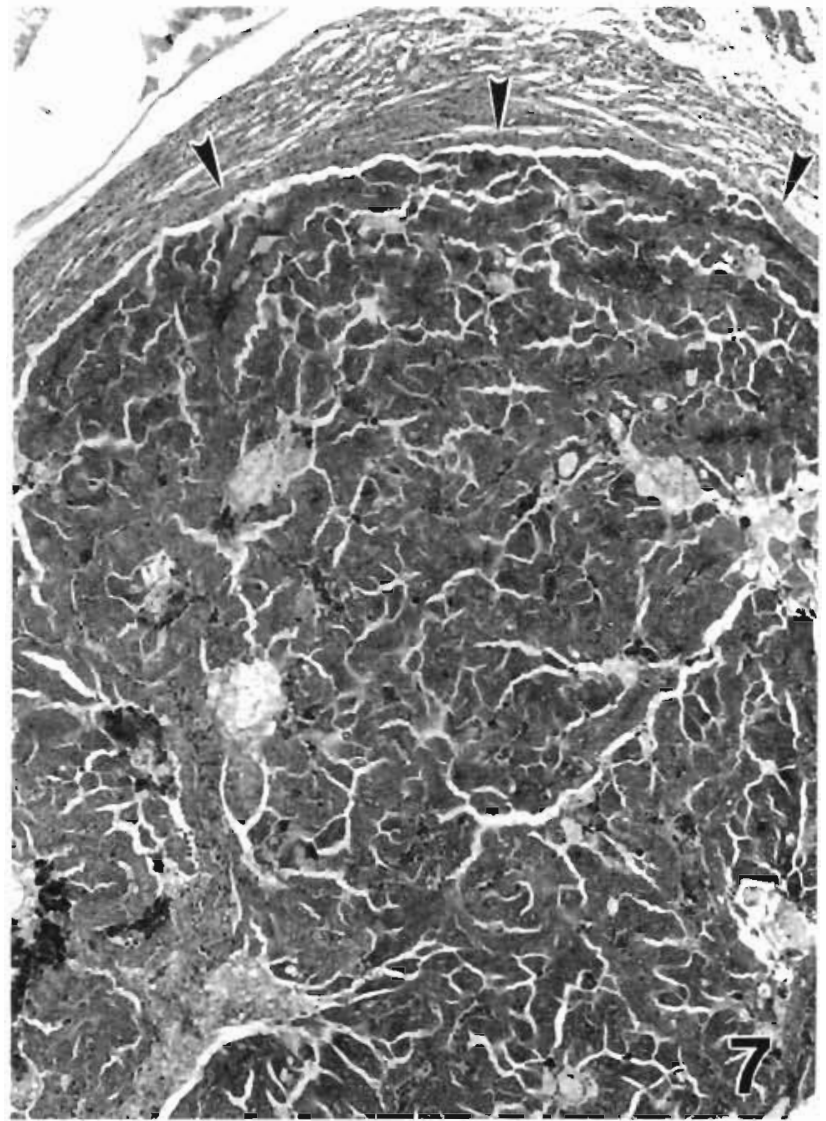

Fig. 7. Poecilia reticulata. Higher magnification of large adenocarcinoma from a control guppy illustrated in Fig. 5 show. ing periphery of neoplasm with normal appearing gas gland epithelial cells (arrowheads). H\&E. $\times 100$

prised of cells exhibiting a prominent tubular or glandular pattern (Fig. 8). The majority of the mass, however, was comprised of basophilic cells arranged in a more solid pattern. Cellular pleomorphism, mitotic figures, and areas of tumor necrosis were common throughout the tumor (Fig. 9). In 2 cases, extensive granulomatous lesions occurred in the gas gland as well as in other visceral organs, particularly liver, spleen and kidney.

\section{DISCUSSION}

The present study showed that swimbladder proliferative lesions are rare in both the medaka and guppy. Correspondingly, in their study on neoplasms of aged untreated medaka, Masahito et al. (1989) did not report any swimbladder lesions. We believe that the swimbladder proliferative lesions in medaka and guppies in the present study were probably spontaneously occurring because they primarily came from control specimens or from tests with compounds that were

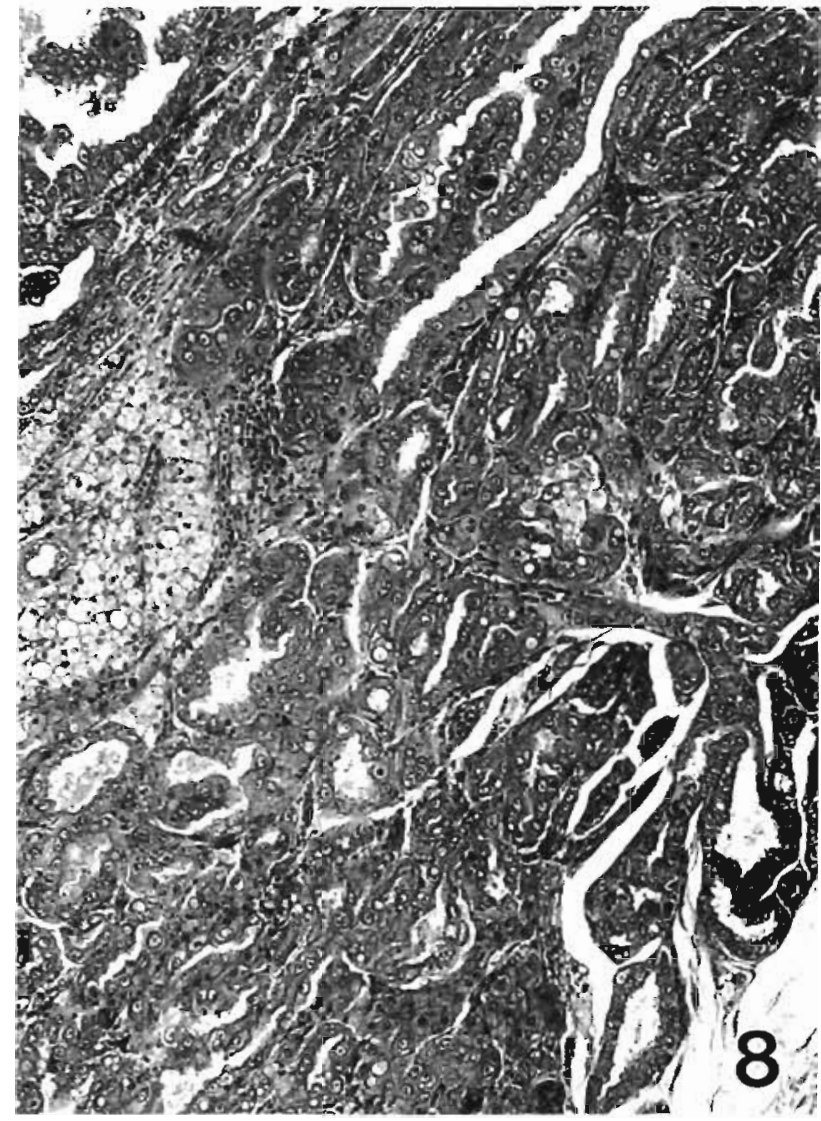

Fig. 8. Poecilia reticulata. Posterior portion of large adenocarcinoma from a control guppy showing prominent glandular pattern. H\&E. $\times 200$

otherwise not carcinogenic to the fish. Similar associations have been seen with respect to some other neoplasms in medaka, including thymic lymphomas (Okihiro \& Hinton 1989, Battalora et al. 1991), exocrine pancreatic carcinomas (Hawkins et al. 1991) and germ cell neoplasms (Hawkins et al. 1996). These neoplasms occurred with a very low overall frequency, $0.3 \%$ for lymphomas (Battalora et al. 1991), 0.08\% for pancreatic neoplasms (Hawkins et al. 1991), and $0.3 \%$ for germ cell neoplasms (Hawkins et al. 1996). None of those types of neoplasms appeared to be associated with carcinogen exposure. For the germ cell neoplasms, however, it was suggested that because multiple cases occurred in fish maintained in the same aquarium or originating from the same cohort, it was possible that culture practices, genetic factors, or a virus may have been involved in the development of these lesions. In a recent study on concentrationresponse effects with diethylnitrosamine in medaka in which more than 5000 medaka were histologically examined, no swimbladder neoplasms were encountered (Walker et al. unpubl.). 


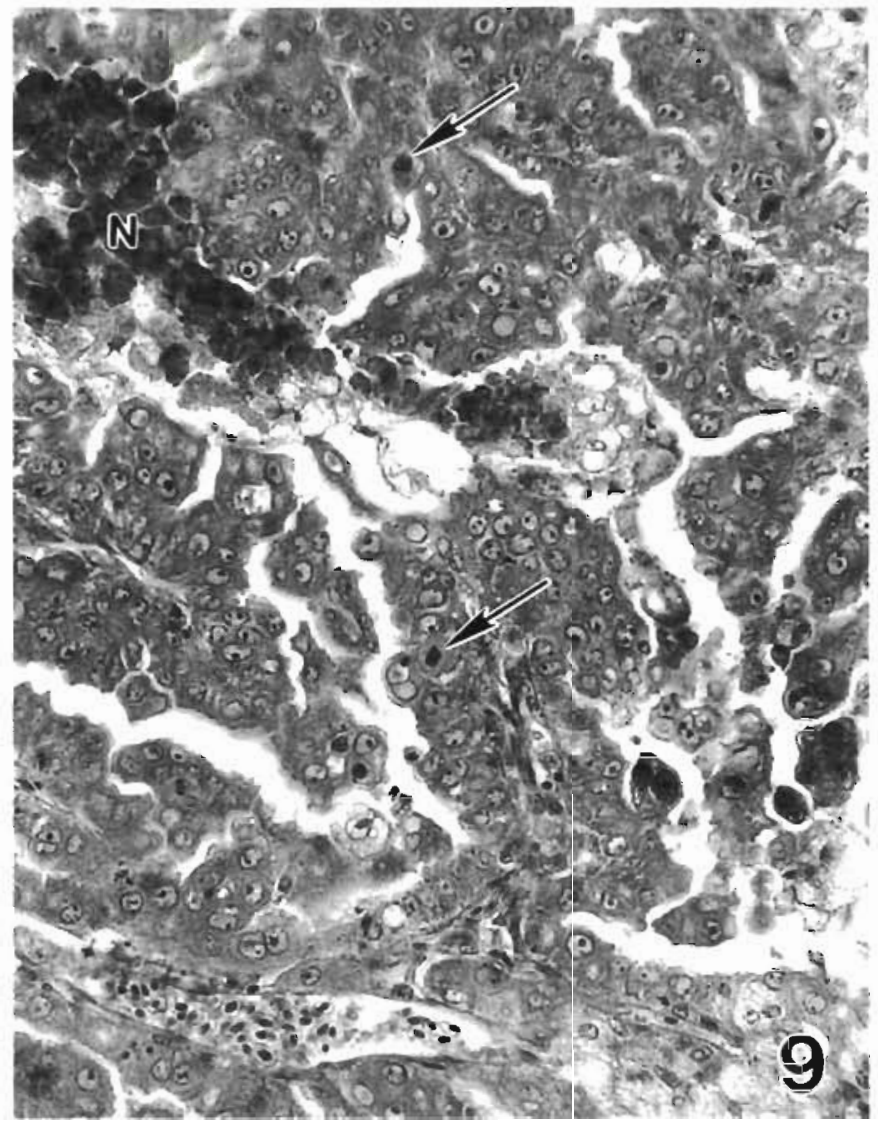

Fig. 9. Poecilia reticulata. Solid area of large carcinoma from a control guppy comprised of basophilic cells. Note cellular pleomorphism, area of tumor necrosis $(N)$, and mitotic figures (arrows). H\&E. $\times 400$

Compared with the medaka, few spontaneous neoplasms have been reported for the guppy, perhaps because fewer have been histologically examined. The guppy has a low spontaneous rate of hepatocellular proliferative lesions (Hawkins et al. 1995). Spontaneous neoplasms of other organs and tissues are likewise rare. Single cases of retinal pigment epithelium adenocarcinoma (Fournie et al. 1992) and chromatophoroma (Hawkins \& Fournie unpubl.) appear to have arisen spontaneously.

Wester \& Canton (1992) described some unusual gas gland lesions in guppies exposed for 3 mo to methyl mercury. Some of the fish had clusters of small basophilic epithelial cells located at the lumenal side of the gland. These cells were atypical and occasionally mitotic, formed tubules, and showed local growth suggestive of invasion. In one case, these cells constituted the major portion of the gland. The cytologic features of those lesions recall features of the small adenocarcinomas from guppies in the present study. In both that study and the present one, the gas gland lesions showed irregular cytomorphology and a tubular growth pattern; however, we saw no evidence of invasion in any of our guppy adenocarcinomas nor any islands of small basophilic epithelial cells.

A high prevalence of swimbladder neoplasms was reported in medaka from preliminary studies designed to validate the medaka carcinogenicity assay for identifying carcinogens among the United States Environmental Protection Agency's priority chemicals (Johnson et al. 1989). These fish were 1 to $4 \mathrm{~d}$ post-hatch at the beginning of the exposure and were exposed in a flow-through system for $28 \mathrm{~d}$. Tumors diagnosed as epitheliomas of the swimbladder secretory epithelium. (gas gland) occurred in 13 of 76 fish (17\%) exposed to $16.5 \mathrm{mg} \mathrm{4}$-chloroaniline $\mathrm{l}^{-1}$, in 7 of 19 fish $(36.7 \%$ ) exposed to $74.3 \mathrm{mg}$ aniline $\mathrm{l}^{-1}$ and in 21 of $31 \mathrm{fish}$ $(67.7 \%)$ exposed to $37.5 \mathrm{mg}$ aniline $\mathrm{l}^{-1}$. Gas gland lesions produced by both compounds were reported to be histologically similar and showed nuclear pleomorphism, multinucleated cells, and high mitotic activity. Tumors often nearly filled the swimbladder but were not invasive. This high prevalence of swimbladder lesions in medaka exposed to aniline and 4-chloroaniline could be related to the age of the fish at initial exposure. At 1 to $4 \mathrm{~d}$ post-hatch, the pneumatic duct was patent and might have contributed to the induction of the lesions. Descriptions of the epitheliomas reported by Johnson et al. (1989) most closely resemble the gas gland epithelium adenomas described in our study from control medaka and guppies.

Low prevalences of swimbladder neoplasms have also been reported in rainbow trout after exposure to several different carcinogens. Swimbladder neoplasms occurred in a single specimen injected intraperitoneally with $\mathrm{BaP}$ (Hendricks et al. 1985), a single specimen exposed as an embryo to an aqueous solution of MNNG (Hendricks et al. 1980), a single fish exposed to an aqueous solution of $\mathrm{MNU}$ as an embryo (Kimura et al. 1981), in 4 of 60 specimens exposed as embryos to MNNG (Kimura et al. 1981) and in 4 of 113 specimens after dietary exposures to DMNM (Hendricks et al. 1995). Higher prevalences of swimbladder neoplasms have also been reported in rainbow trout from 2 other carcinogen exposures (Bailey et al. 1984). Fingerlings exposed to $100 \mathrm{ppm}$ DEN in water for $3 \mathrm{wk}$ resulted in 10 of $42(24 \%)$ specimens with neoplasms and swim up fry exposed to $50 \mathrm{ppm}$ MNNG in water for 30 min resulted in 11 of $24(46 \%)$ specimens with neoplasms. In all cases, the lesions were described as papillary adenomas of the swimbladder mucosal epithelium and were composed of well-differentiated, tall columnar cells. Because salmonids are physostomous (i.e. swimbladders do have patent connections with the alimentary canal) and lack a gas gland, the tumors arose from the single-layered swimbladder epithelium. The salmonid neoplasms were histologically distinct 
from the neoplasms described from medaka or guppies in the present study and from those described by Johnson et al. (1989), both of which arose from the gas gland epithelium.

There are several important reasons for reporting on and studying the occurrence and biology of spontaneous and rare neoplasms in small fish carcinogenesis models. In developing and conducting carcinogenesis bioassays, it is essential to know as much as possible about the capability of the model to develop any kind of neoplastic lesion, whether spontaneous or chemically induced. These types of studies are particularly important for species that are widely used for carcinogenicity testing, such as the medaka and the guppy. Furthermore, the carcinogenic potency and target organs of a test compound could be misinterpreted if the historical incidence of rare extrahepatic neoplasms is not known or considered. One of the clear advantages of using the small-fish models in bioassays is the statistical power achieved by being able to use large numbers of specimens in the studies. This facilitates determining whether or not a test compound induced a rarely-occurring lesion.

Acknowledgements. We thank Lee Courtney for printing the figures and Valerie Coseo for typing the manuscript. This paper is contribution number 1071 of the U.S. Environmental Protection Agency, National Health and Environmental Effects Research Laboratory, Gulf Breeze. This study was supported in part by the U.S. Army Biomedical Research and Development Command.

\section{LITERATURE CITED}

Battalora MStJ, Hawkins WE, Walker, WW, Overstreet RM (1991) Occurrence of thymic lymphoma in carcinogenesis bioassay specimens of the Japanese medaka (Oryzias latipes). Cancer Res (Suppl) 50:5675-5678

Bailey GS, Hendricks JD, Nixon JE, Pawlowski NE (1984) The sensitivity of rainbow trout and other fish to carcinogens. Drug Metab Rev 15:725-750

Duncan IB (1978) Evidence for an oncovirus in swimbladder fibrosarcoma of Atlantic salmon Salmo salar L. J Fish Dis $1: 127-131$

Ferguson HW (1989) Systemic pathology of fish. Iowa State University Press, Ames

Fournie JW, Hawkins WE, Walker WW (1992) Adenocarcinoma of the retinal pigment epithelium in the guppy Poecilia reticulata Peters. J Comp Pathol 106:429-434
Hawkins WE, Fournie JW, Battalora MStJ, Walker WW (1991) Carcinoma of the exocrine pancreas in medaka. J Aquat Anim Health 3:213-220

Hawkins WE, Walker WW, Overstreet RM (1995) Practical carcinogenicity tests with small fish species. In: Rand GM (ed) Fundamentals of aquatic toxicology: effects, environmental fate, and risk assessment. Taylor and Francis, Washington, DC, p 421-446

Hawkins WE, Fournie JW, Ishikawa T, Walker WW (1996) Germ cell neoplasms in Japanese medaka. J Aquat Anim Health 8:120-129

Hendricks JD, Scanlan RA, Williams JL, Sinnhuber RO, Grieco MP (1980) Carcinogenicity of $\mathrm{N}$-methyl-N'-nitro$\mathrm{N}$-nitrosoguanidine to the livers and kidneys of rainbow trout (Salmo gairdneri) exposed as embryos. J Natl Cancer Inst 64:1511-1519

Hendricks JD, Meyers TR, Shelton DW, Casteel JL, Bailey GS (1985) Hepatocarcinogenicity of benzo(a)pyrene to rainbow trout by dietary exposure and intraperitoneal injection. J Natl Cancer Inst 74:839-851

Hendricks JD, Shelton DW, Loveland PM, Pereira CB, Bailey GS (1995) Carcinogenicity of dietary dimethylnitrosomorpholine, N-methyl-N'-nitro-N-nitrosoguanidine, and dibromoethane in rainbow trout. Toxicol Pathol 23:447-457

Humason GL (1979) Animal tissue techniques, 4th edn. Freeman, San Francisco, CA

Johnson R, Tietge J, Stokes G (1989) Validation of the medaka assay for chemical carcinogens. Compendium of the FY 1988 and 1989 Research Reviews for the Research Methods Branch. US Army Biomedical Research and Development Laboratory, Fort Detrick, MD, p 45-60

Kimura I, Kitaori $\mathrm{H}$, Yoshizaki K, Tayama K, Ito M, Yamada S (1981) Development of tumors in rainbow trout following embryonic exposure to $\mathrm{N}$-nitroso compounds. In: Dawe CJ, Harshbarger JC, Kondo S, Sugimura T, Takayama S (eds) Phyletic approaches to cancer. Japan Scientific Societies Press, Tokyo, p 241-252

Masahito P, Aoki K, Egami N, Ishikawa T, Sugano H (1989) Life-span studies on spontaneous tumor development in the medaka (Oryzias latipes). Jpn J Cancer Res 80: $1058-1065$

McKnight IJ (1978) Sarcoma of the swim bladder of Atlantic salmon (Salmo salar L.). Aquaculture 13:55-60

Okihiro MS, Hinton DE (1989) Lymphoma in the Japanese medaka (Oryzias latipes). Dis Aquat Org 7:79-87

Walker WW, Overstreet RM, Manning CS, Hawkins WE (1985) Small aquarium fishes as models for environmental carcinogenesis: exposure methodology. J Appl Toxicol 5: 255-260

Wester PW, Canton JH (1992) Histopathological effects in Poecilia reticulata (guppy) exposed to methyl mercury chloride. Toxicol Pathol 20:81-92

Wester PW, Canton JH, Van Ieserl AAJ, Krajnc EI, Vaessen HAMG (1990) The toxicity of bis(tri-n-butyltin) oxide (TBTO) and di-n-butyltindichloride (BBTC) in the small fish species Oryzias latipes (medaka) and Poecilia reticulata (guppy). Aquat Toxicol 16:53-72

Submitted: May 18, 1999; Accepted: July 9, 1999

Proofs received from author(s): October 20, 1999
Editorial responsibility: Nicolaus Peters,

Hamburg, Germany 